\title{
Gerontology
}

\section{Iridescent Life Course: LGBTQ Aging Research and Blueprint for the Future - A Systematic Review}

\author{
Karen I. Fredriksen Goldsen ${ }^{a}$ Sarah Jen $^{b} \quad$ Anna Muraco $^{c}$ \\ ${ }^{a}$ School of Social Work, University of Washington, Seattle, WA, USA; ${ }^{b}$ School of Social Welfare, University of Kansas, \\ Lawrence, KS, USA; ' Department of Sociology, Loyola Marymount University, Los Angeles, CA, USA
}

\section{Keywords}

LGBTQ · Aging · Review · Life course · Queering ·

Trans-forming

\begin{abstract}
Background: LGBTQ* (lesbian, gay, bisexual, trans, and queer) older adults are demographically diverse and growing populations. In an earlier 25-year review of the literature on sexual orientation and aging, we identified four waves of research that addressed dispelling negative stereotypes, psychosocial adjustment to aging, identity development, and social and community-based support in the lives of LGBTQ older adults. Objectives: The current review was designed to develop an evidence base for the field of LGBTQ aging as well as to assess the strengths and limitations of the existing research and to articulate a blueprint for future research. Methods: Using a life course framework, we applied a systematic narrative analysis of research on LGBTQ aging. The review included 66 empirical peer-reviewed journal articles (2009-2016) focusing on LGBTQ adults aged 50 years and older, as well as age-based comparisons (50 years and older with those younger). Results: A recent wave of research on the health and well-being of LGBTQ older adults
\end{abstract}

was identified. Since the prior review, the field has grown rapidly. Several findings were salient, including the increased application of theory (with critical theories most often used) and more varied research designs and methods. While existing life course theory provided a structure for the investigation of the social dimensions of LGBTQ aging, it was limited in its attention to intersectionality and the psychological, behavioral, and biological work emerging in the field. There were few studies addressing the oldest in these communities, bisexuals, gender non-binary older adults, intersex, older adults of color, and those living in poverty.

This paper was originally presented at the 21st International Association of Gerontology and Geriatrics World Congress, July 2017, San Francisco, CA, USA. LGBTQ* is used as it reflects the state of the terms used in the literature, which connotes lesbian (L), gay (G), bisexual (B), trans/transgender ( $T$, as an umbrella term to include trans, transgender, gender diverse, and gender non-binary), and queer ( $Q$, as an umbrella term to include queer, sexual diverse, and non-binary). Cisgender is used to "refer to individuals who have a match between the gender they were assigned at birth, their bodies, and their personal identity" [1]. Heteronormative is used in the literature to connote the assumption of heterosexuality as normative and naturally occurring according to heterosexual attraction between two differently sexed and gendered bodies and that organizes societal systems [1].

\section{KARGER}

(C) 2019 S. Karger AG, Base

E-Mail karger@karger.com

www.karger.com/ger
Karen I. Fredriksen Goldsen, $\mathrm{PhD}$

School of Social Work, University of Washington

4101 15th Ave. NE, Box 354900

Seattle, WA 98105 (USA)

E-Mail fredrikk@uw.edu 
Conclusions: The Iridescent Life Course framework highlights the interplay of light and environment, creating dynamic and fluid colors as perceived from different angles and perspectives over time. Such an approach incorporates both queering and trans-forming the life course, capturing intersectionality, fluidity over time, and the psychological, behavioral, and biological as well as social dimensions of LGBTQ aging. Work is needed that investigates trauma, differing configurations of risks and resources over the life course, inequities and opportunities in representation and capital as LGBTQ adults age, and greater attention to subgroups that remain largely invisible in existing research. More depth than breadth is imperative for the field, and multilevel, longitudinal, and global initiatives are needed.

(c) 2019 S. Karger AG, Basel

\section{Introduction}

Mirroring rapid changes in policies related to samesex marriage, there has been a significant increase in public attention to lesbian, gay, bisexual, transgender, and queer (LGBTQ*) issues across the globe. For example, between 2001 and 2016, public support in the USA for same-sex marriage grew steadily from 35 to $55 \%$ [2], culminating in the 2015 Obergefell v. Hodges Supreme Court decision giving same-sex couples the constitutional right to marry. Despite increasingly positive societal discourse regarding LGBTQ people in many parts of the world, those in older adulthood remain largely invisible. The Institute of Medicine [3] identified LGBT older adults as an underserved and understudied population, calling for more research to address their distinct needs.

The proportion of older adults continues to grow faster than any other segment of the population worldwide, and the USA is no exception, with the population 65 years and older expected to more than double in size from 40.2 to 88.5 million between 2010 and 2050 [4]. The older adult population is also increasingly diverse by race and ethnicity [5], as well as by sexual and gender identity [6]. Individuals who openly self-identify as LGBTQ are estimated to comprise $2.4 \%$ of the USA older adult population or 2.7 million individuals, which will increase to more than 5 million by 2060. Furthermore, when taking into consideration same-sex behavior, attractions, and romantic relationships, this number more than doubles to over 5 million LGBTQ older adults today and more than 20 million by 2060 [6].

An earlier 25-year review of existing research on sexual orientation and aging [7] analyzed 58 articles pub- lished between 1984 and 2008. The review assessed the literature corresponding to the dimensions of the life course perspective as explicated by Elder [8]. Based on the analysis using life course theory, the review identified four key waves in sexual orientation and aging related research, illustrating the evolution of the field. The first wave of research dispelled myths and negative stereotypes of sexual-minority older adults as lonely, isolated, and having poor mental health, illuminating similarities between lesbian, gay, and bisexual older adults and their heterosexual counterparts. A second wave emphasized psychosocial adjustment to aging, while the third focused on identity development and recognized the shifting historical and social contexts. The fourth wave emphasized sexual-minority adults' social relationships and community-based needs and support.

The two primary life course themes in the existing literature at the time were the interplay of lives with historical times and social relationships. The existing studies explored how lesbian, gay, and bisexual older adults' experiences intersected with the broader historical and social context in which they lived, including how experiences of prejudice affected their aging, identity, and service utilization. This early research also sought to understand the importance of linked lives and social interactions, including the importance of families of choice, legally defined family members, and social and community support networks. The review identified the life course tenets of timing of lives and agency as significantly underdeveloped and requiring further study.

In this paper, we examine articles published since the previous review to provide an evidence base for this growing field. Given recent changes in the expanding empirical literature, we also expanded the population of interest to include trans and queer older adults. By synthesizing research findings across 66 articles published between 2009 and 2016 that focus on LGBTQ older adults and aging, we examine the key life course themes in the literature, as well as the theoretical, substantive, and methodological limitations and strengths of the literature base. By assessing the extent to and ways in which knowledge in the field has advanced, as well as examining existing gaps in the research, we outline the Iridescent Life Course framework with a blueprint for future research. We propose the Iridescent Life Course to capture the diverse, fluid, and intersectional nature of LGBTQ older adults' lived lives, much like iridescent properties creating dynamic and fluid colors as perceived from different angles, perspectives, and environments over time. 
Table 1. Literature review search terms

\begin{tabular}{|c|c|c|c|c|c|}
\hline & Sexuality & Sexual minority & Sexual identities & Trans* & Gender expression \\
\hline $\begin{array}{l}\text { Sexuality and } \\
\text { gender related }\end{array}$ & $\begin{array}{l}\text { sexual orientation } \\
\text { sexual attraction } \\
\text { sexual behavior } \\
\text { sexual preference } \\
\text { sexual identity } \\
\text { homosexuality } \\
\text { bisexuality }\end{array}$ & $\begin{array}{l}\text { sexual minority } \\
\text { sexual minorities } \\
\text { sexual minority men } \\
\text { sexual minority women }\end{array}$ & $\begin{array}{l}\text { homosexual } \\
\text { non-heterosexual } \\
\text { bisexual } \\
\text { lesbian } \\
\text { gay } \\
\text { queer }\end{array}$ & $\begin{array}{l}\text { transgender } \\
\text { trans } \\
\text { transgendered } \\
\text { transgenders }\end{array}$ & $\begin{array}{l}\text { gender queer } \\
\text { gender identity } \\
\text { gender expression } \\
\text { gender non-binary } \\
\text { gender non-conforming } \\
\text { gender expansive } \\
\text { gender diverse }\end{array}$ \\
\hline \multicolumn{6}{|l|}{ AND } \\
\hline Aging related & $\begin{array}{l}\text { aging } \\
\text { older adults } \\
\text { elder } \\
\text { gerontology }\end{array}$ & & & & \\
\hline
\end{tabular}

$\operatorname{Trans}^{*}$ is an umbrella term used to connote transgender identities, including gender non-binary and diverse.

\section{Methodology}

Like prior gerontological literature reviews $[9,10]$, we used a narrative systematic approach to structure the analysis and comparison of studies by identifying concepts according to key words, as opposed to a meta-analytic method, which analyzes studies according to the measurement of concepts [11]. The application of a meta-analytic approach is limited in fields that are underdeveloped and made up of a wide range of disciplinary and methodological approaches. In contrast, a narrative approach provides the foundation for assessing the comparability and divergence in findings, as well as the relative strengths and limitations across studies, despite the wide range of methods used.

This review included peer-reviewed journal articles published between 2009 and 2016 focusing on LGBTQ adults aged 50 years and older, as well as those including age-based comparisons of those 50 years and older with younger counterparts. As in the previous review, articles that were written in English and contained original empirical findings published in a peer-reviewed journal with 4 or more study participants were included. A Boolean phrase search was applied to the following databases: PsycINFO, Sociological Abstracts, and MedlinePlus. Multiple search terms were included: sexuality, sexual minorities, sexual identities, lesbian, gay, bisexual, transgender, trans, queer, and gender. These search terms were then combined with aging-related terms: aging, older adults, elder, and gerontology (Table 1). Articles that focused specifically on HIV/AIDS were excluded, since that body of literature has been the focus of several recent reviews among both older adults $[11,12]$ and the broader population [13-15].

Figure 1 represents a flowchart of the search process, with a final sample of 66 articles. Two articles included findings from multiple studies; therefore, while 66 articles were included, study design and sample characteristics are reported for a total of 70 studies. In all, 185 articles were excluded based on sample ineligibility (e.g., did not include LGBTQ adults over the age of 50 years). The articles were systematically reviewed by two graduate students and

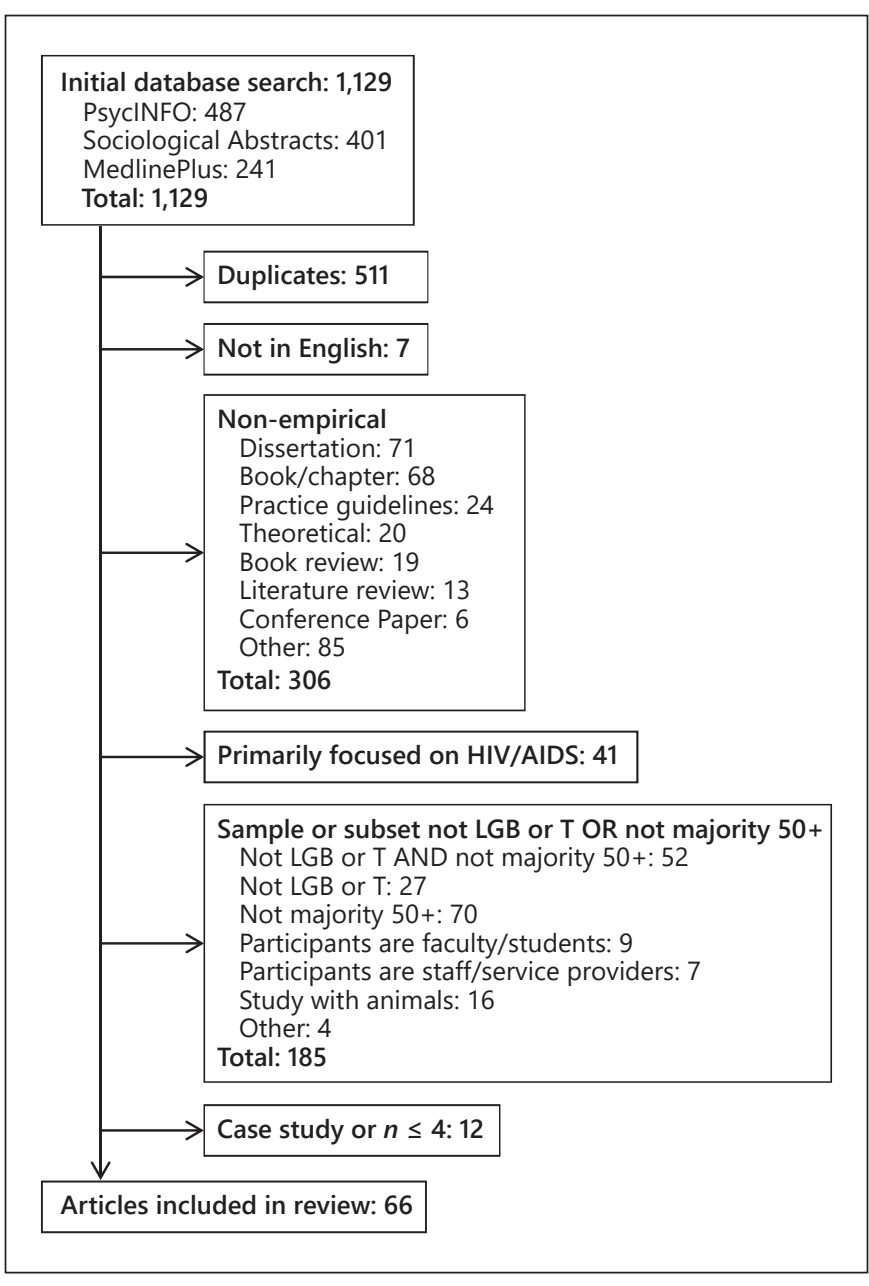

Fig. 1. Search flow diagram. 
coded by study type, research design and method, theory, population definition, sample characteristics, salient findings, and limitations. See Table 2 for an overview of the articles included in the review.

All authors analyzed each dimension across the full range of articles. Data on sample characteristics, study design, recruitment procedures, and methods were compiled across the articles to analyze the representation of various populations and common strengths and limitations in terms of the sampling procedures and methods applied. Theories were organized into substantive and methodological theories to assess what number of articles applied a theoretical framework or theoretical concepts, which revealed the extent of theory used across articles and common theoretical concepts represented. Salient findings were analyzed next to assess the topical domain areas represented in the field and how they corresponded to the four existing dimensions of the life course perspective, which enabled a comparison of how trends in the field and areas of focus had shifted over time.

\section{Results}

\section{Study Design and Sample Characteristics}

All studies were cross-sectional. More than half (56.3\%) used quantitative methods, $39.4 \%$ used qualitative methods, and 3 studies applied mixed methods. Data collection included surveys (56.3\%), interviews (35.2\%), and focus groups $(7.0 \%, n=5)$. Three studies also used participant observation in addition to interviews [16-18]. A majority of the studies relied on community-based samples $(85.1 \%)$, with $4.5 \%$ utilizing population-based representative data $(n=3)$ [19-21]. Most of the studies incorporated multiple types of recruitment, most commonly outreach via health, social, and other communitybased service organizations or businesses (54.8\%), snowball sampling (27.4\%), internet/social media (23.3\%), and flyers and publications such as newsletters and newspapers (20.5\%). Two studies used public venues or events. The recruitment process was not described for $23.3 \%$ of the studies. Secondary data analyses were used in $18.9 \%$ of the studies.

Sample sizes ranged from 6 to 256,585 participants, with a median size of 151 participants. Most studies (71.2\%) included only participants aged 50 years and older, $16.9 \%$ had participants aged 60 years and older, and $5.6 \%(n=4)$ had participants aged 65 years and older. Participants younger than 50 years were included in $21.1 \%$ of the studies, which incorporated age-based comparisons. While the majority of the studies reported on a USA sample (73.2\%), 4 studies reported on international samples [22-25]; $21.1 \%$ had samples exclusively from outside the USA, including Australia [26, 27], Canada $[28,29]$, Hong Kong [30], Israel [31], the Netherlands [32,
33], New Zealand [34, 35], Sweden [36], and the UK [18, 37-39].

The population of interest varied in definition and measurement across studies. The most common aspect of sexuality identified for study in the articles was sexual orientation, most often measured with a single sexual identity question. The most common response categories were "lesbian," "gay," "bisexual," and "heterosexual" or "straight." Less frequent responses included "homosexual" in place of or in addition to "gay" and "lesbian" (reported in $8.1 \%$ of the studies, $n=6)$, "queer" $(8.1 \%, n=$ 6 ), and "questioning" (5.4\%, $n=5)$, and 3 studies reported "pansexual/omnisexual." Three studies used "celibate/ asexual" (4.1\%), 2 used "dyke" and "woman loving woman" $[28,29]$, and 1 used "same-gender-loving" [40]. Three studies reported on sexual behavior, primarily "men who have sex with men" [41-43].

A majority of the studies included participants across multiple sexual identities (69.0\%), most often lesbian-, gay-, and bisexual-identified older adults $(28.2 \%)$, followed by $9.9 \%$ including only lesbian- and gay-identified individuals $(n=7)$, and $14.1 \%$ comparing with heterosexuals. Eighteen studies included a single sexual identity group, including $12.7 \%$ with gay men only and $12.7 \%$ with lesbians only. While $51.4 \%$ of the studies included bisexuals, no studies had only bisexuals. Four studies did not report the sexual orientation or identity of the participants, but instead referred to the population of interest as sexual and/or gender minorities or members of "same-sex" couples.

Gender and gender identity were assessed through a variety of means. Approximately $10 \%(9.9 \%, n=7)$ of the studies included only trans-identified participants, with an additional $19.7 \%$ including some trans participants. The most common terms used to assess trans identities were "transgender" (18.3\%), "MTF" (male to female) $(8.1 \%, n=6)$, and "FTM" (female to male) $(4.2 \%, n=3)$. In 2 studies, a broader range of terms were used to refer to gender identity and expression, including "transsexual," "genderqueer," "gender bender," "trans-blended," "third gender," "cisgender," "cismale," "cisfemale," "masculine," "feminine," "two spirit," and "androgynous." Some studies included women only (15.5\%) or men only (15.5\%). Other studies used sex, gender, and/or sexual identity-related terms interchangeably. For instance, 1 study assessed sex as being "male" or "female," but referred to the participants as "men" or "women." Another assessed trans individuals via a sexual identity question. Only 1 study included intersex participants. 


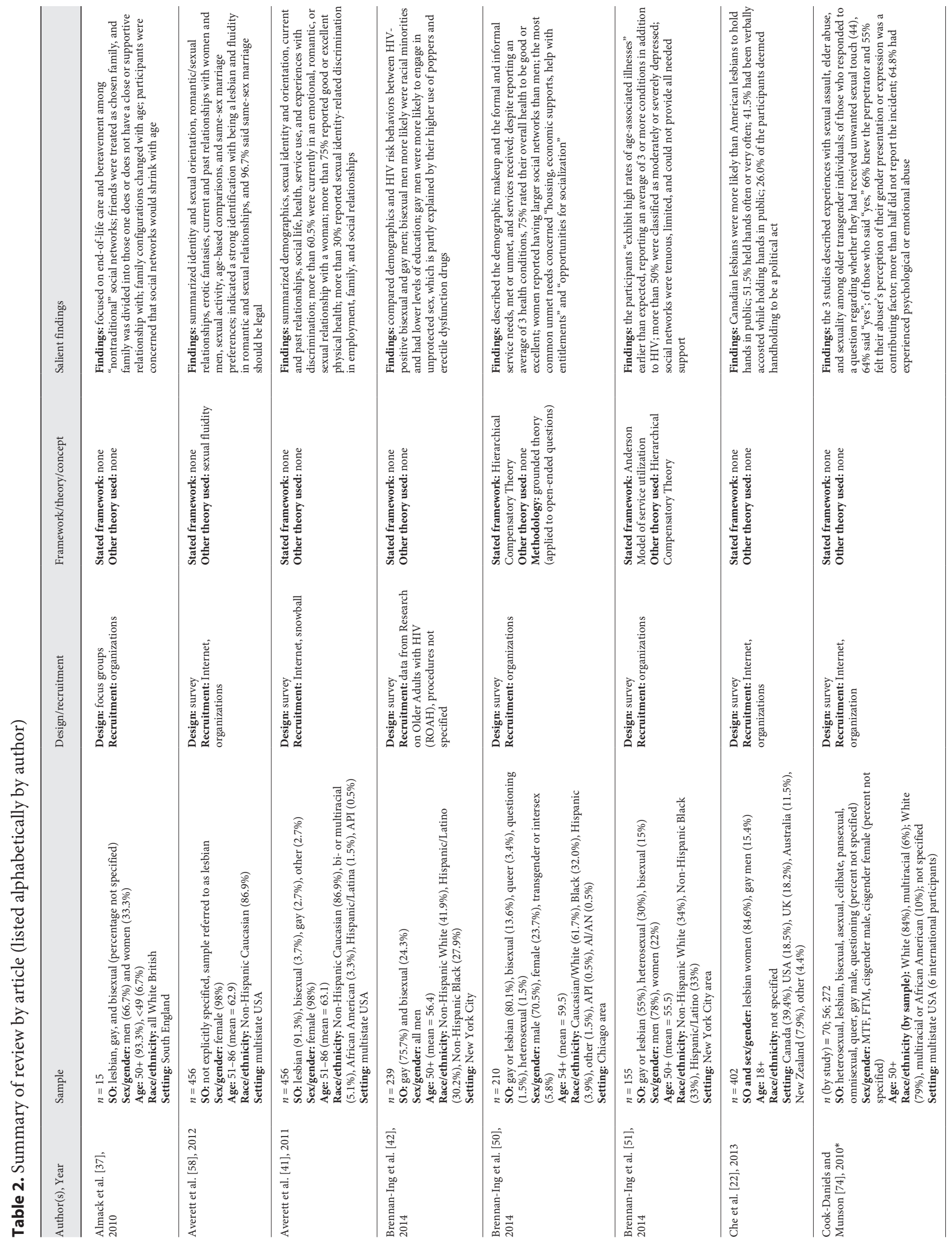




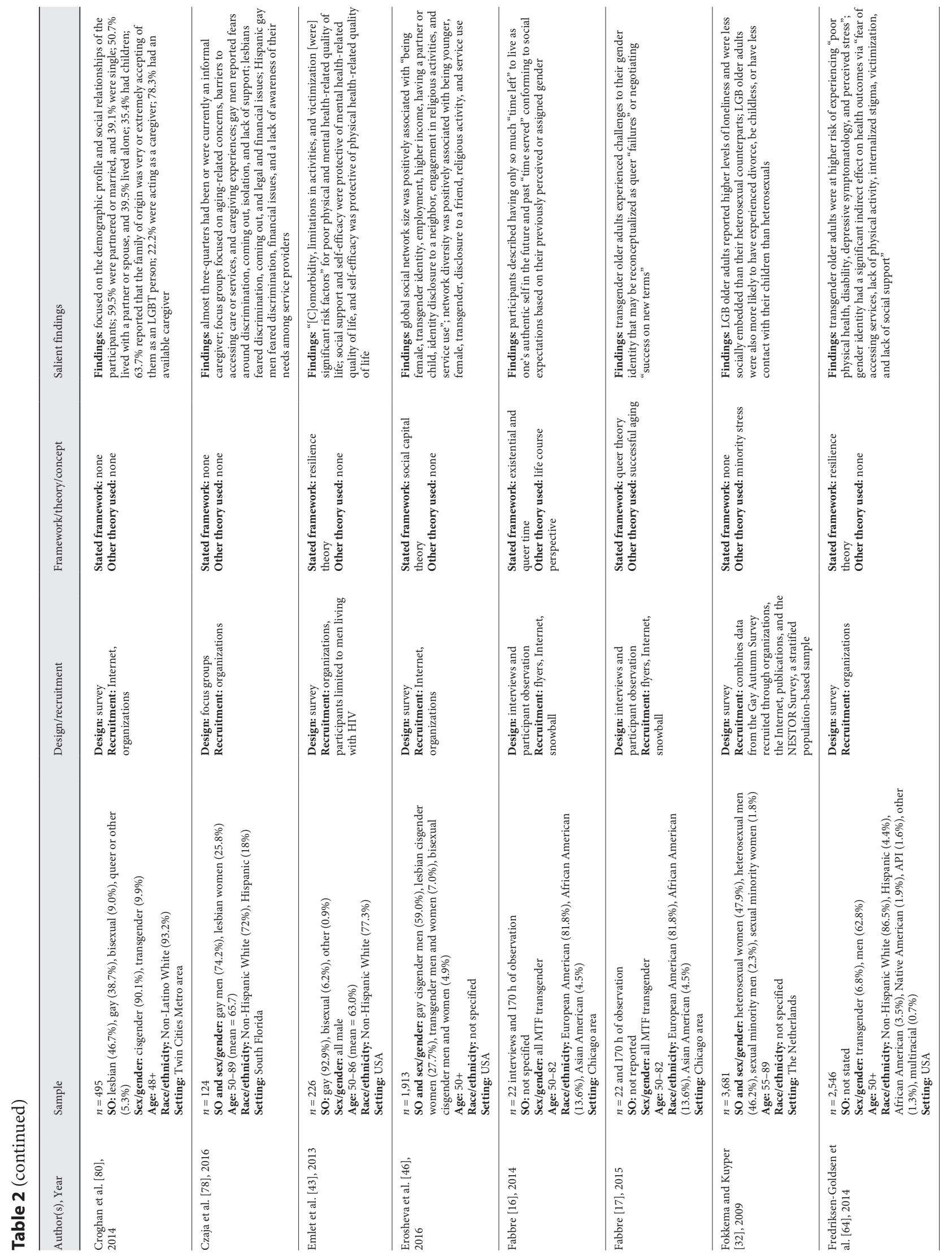




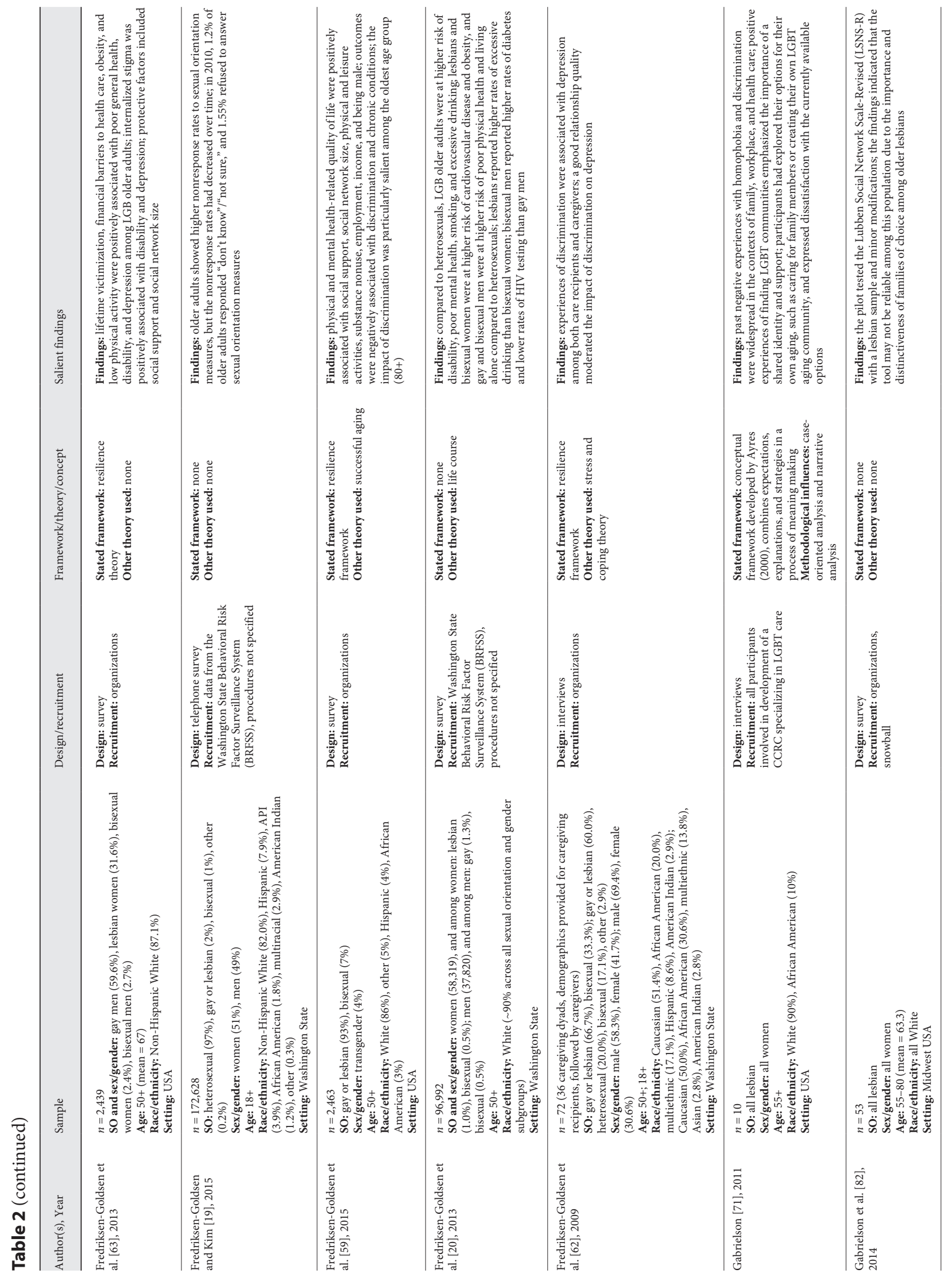




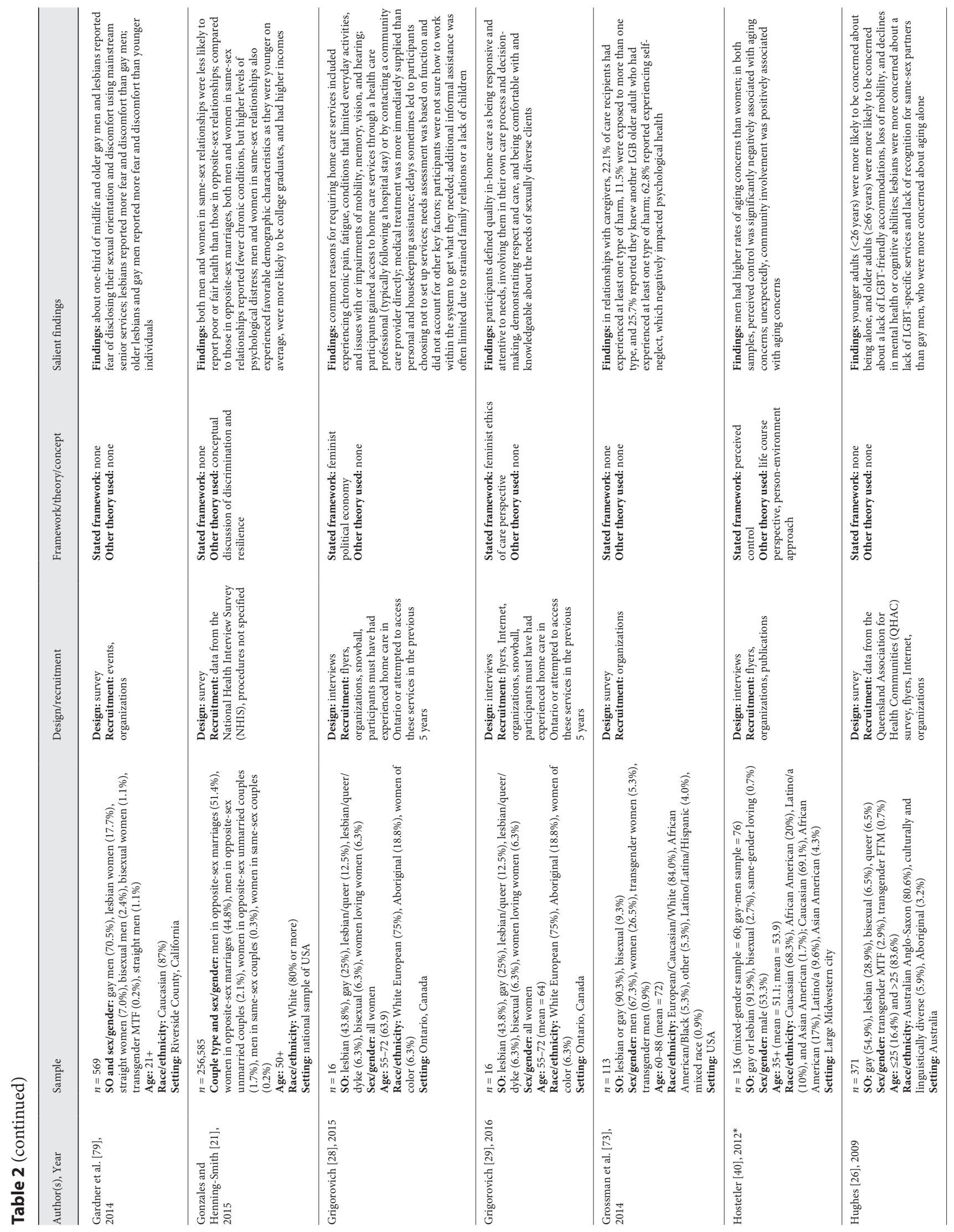




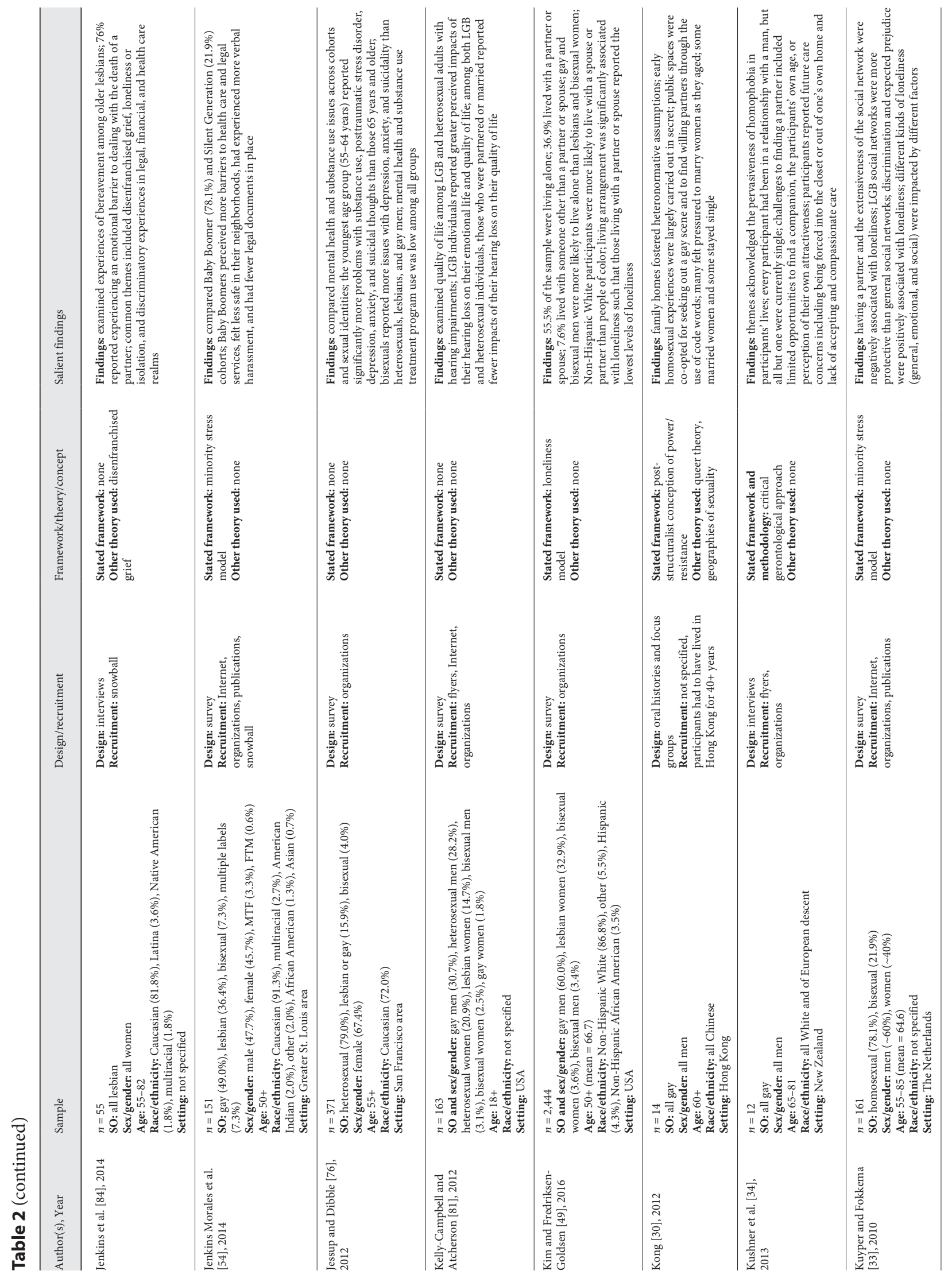




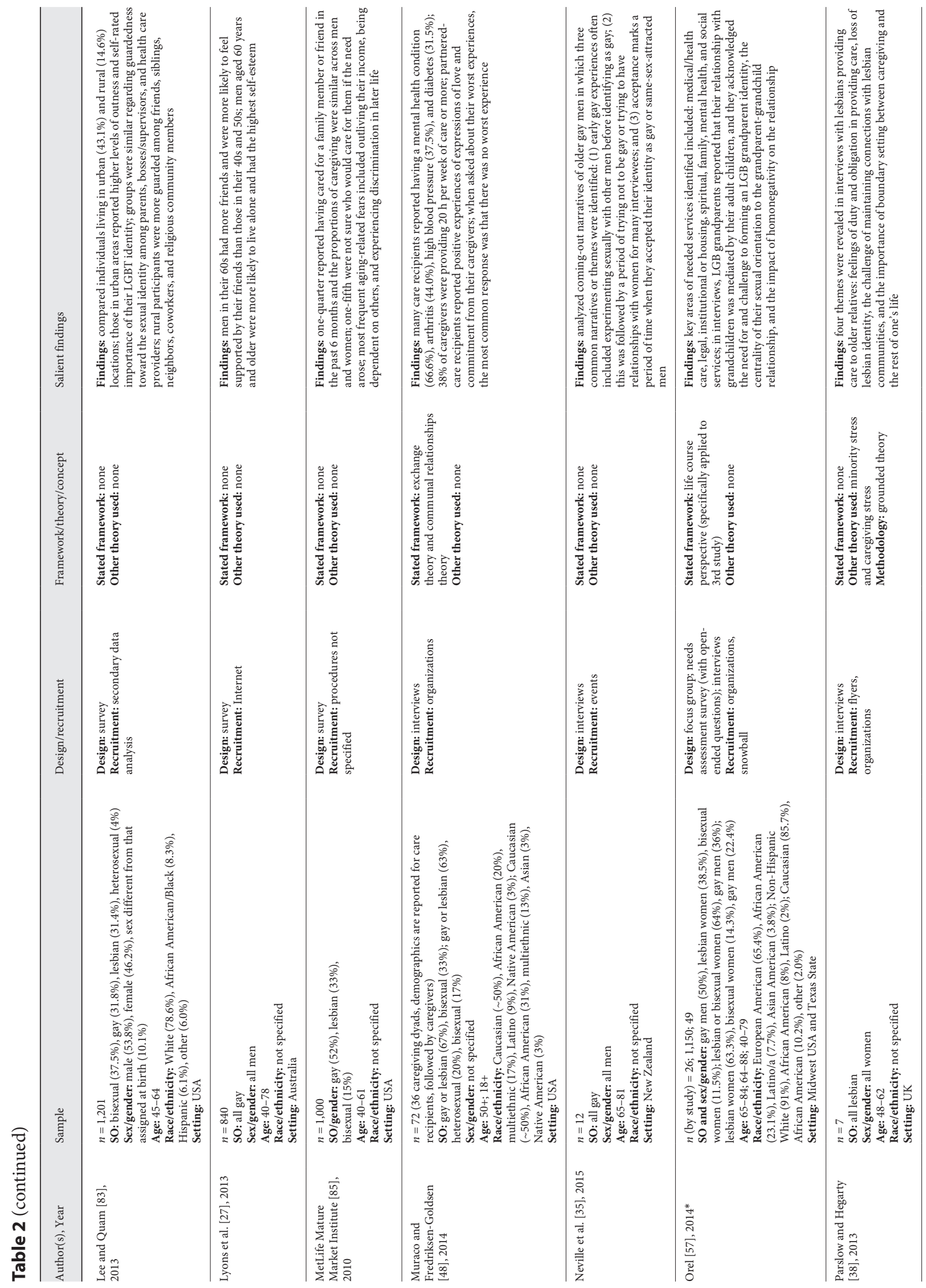




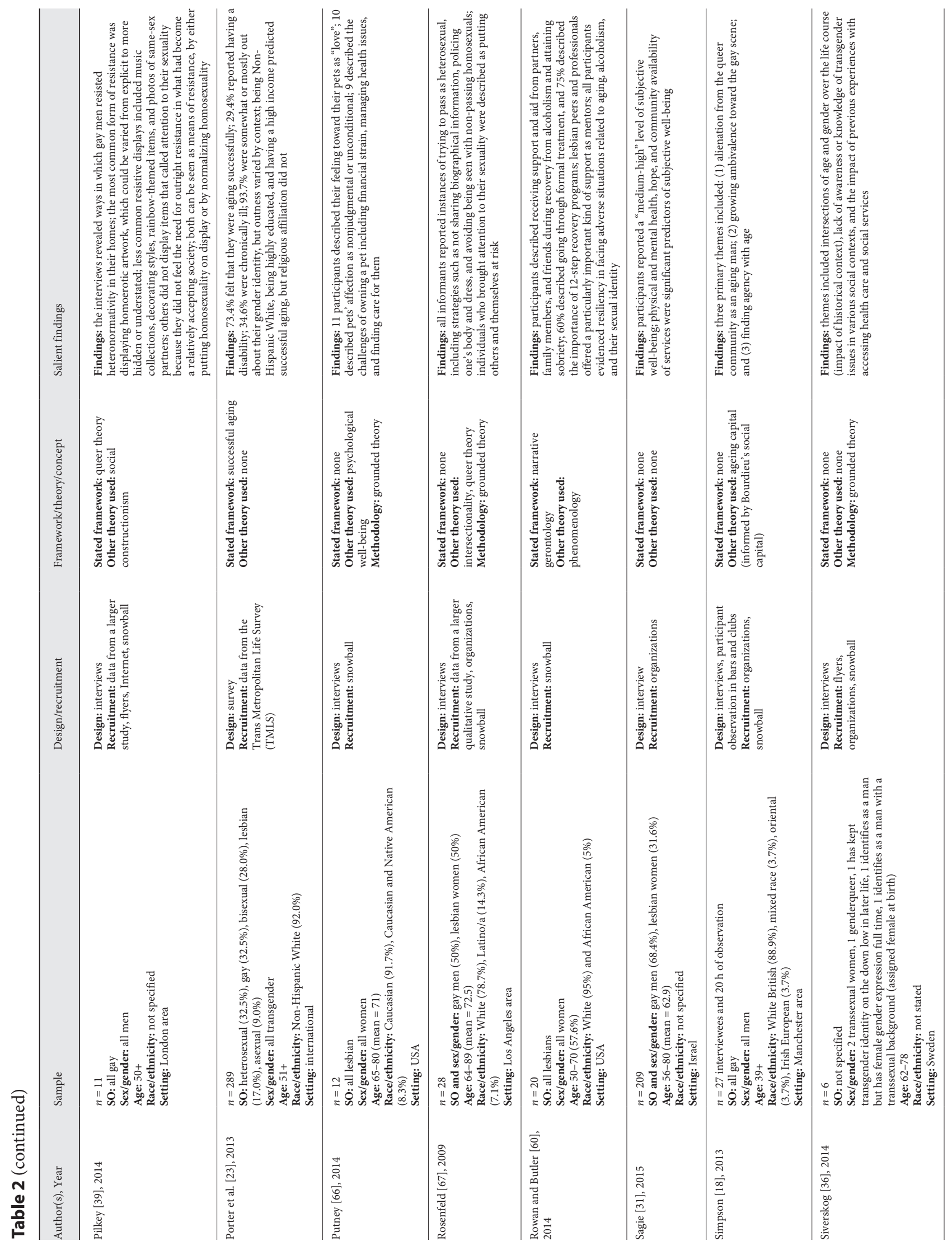




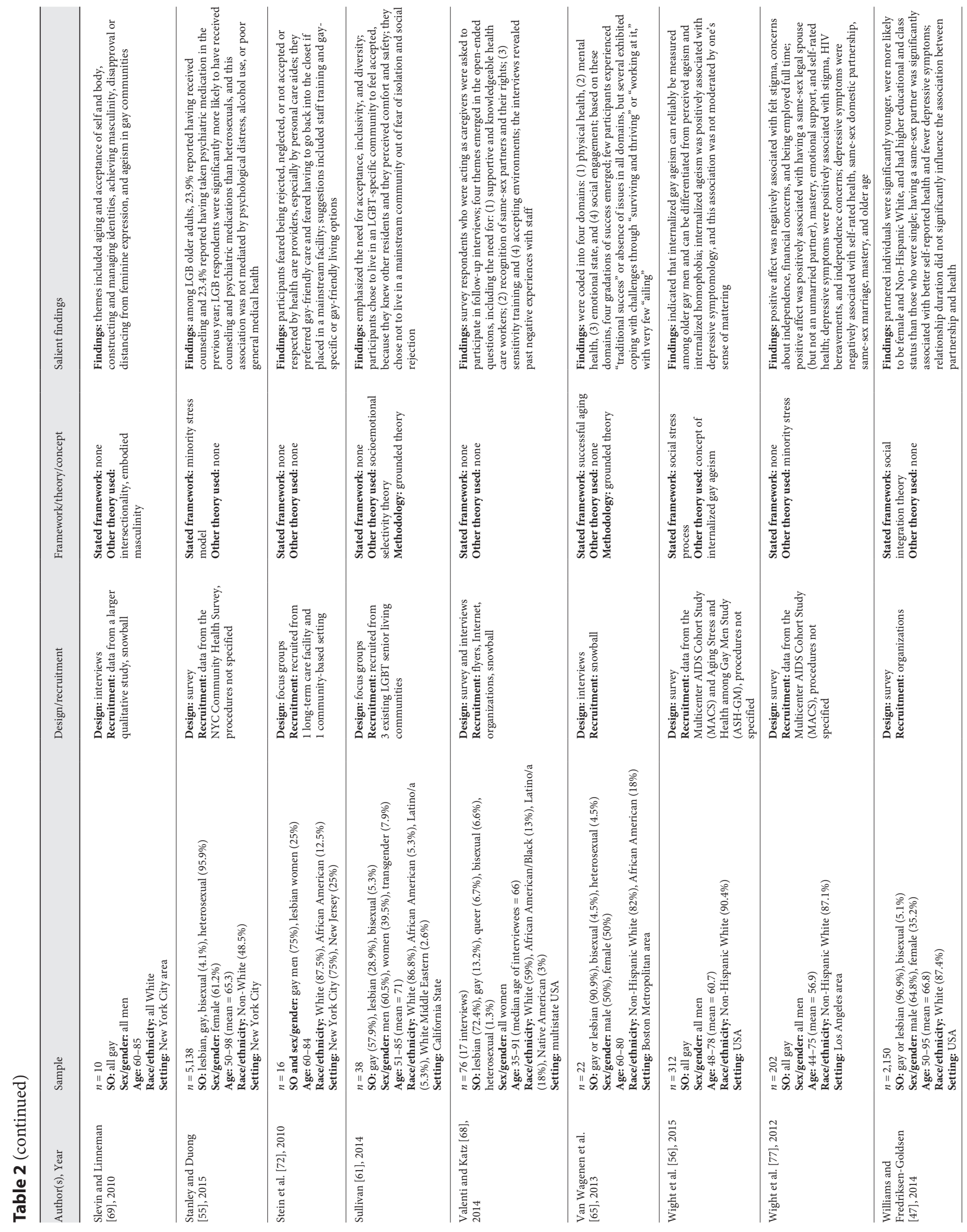




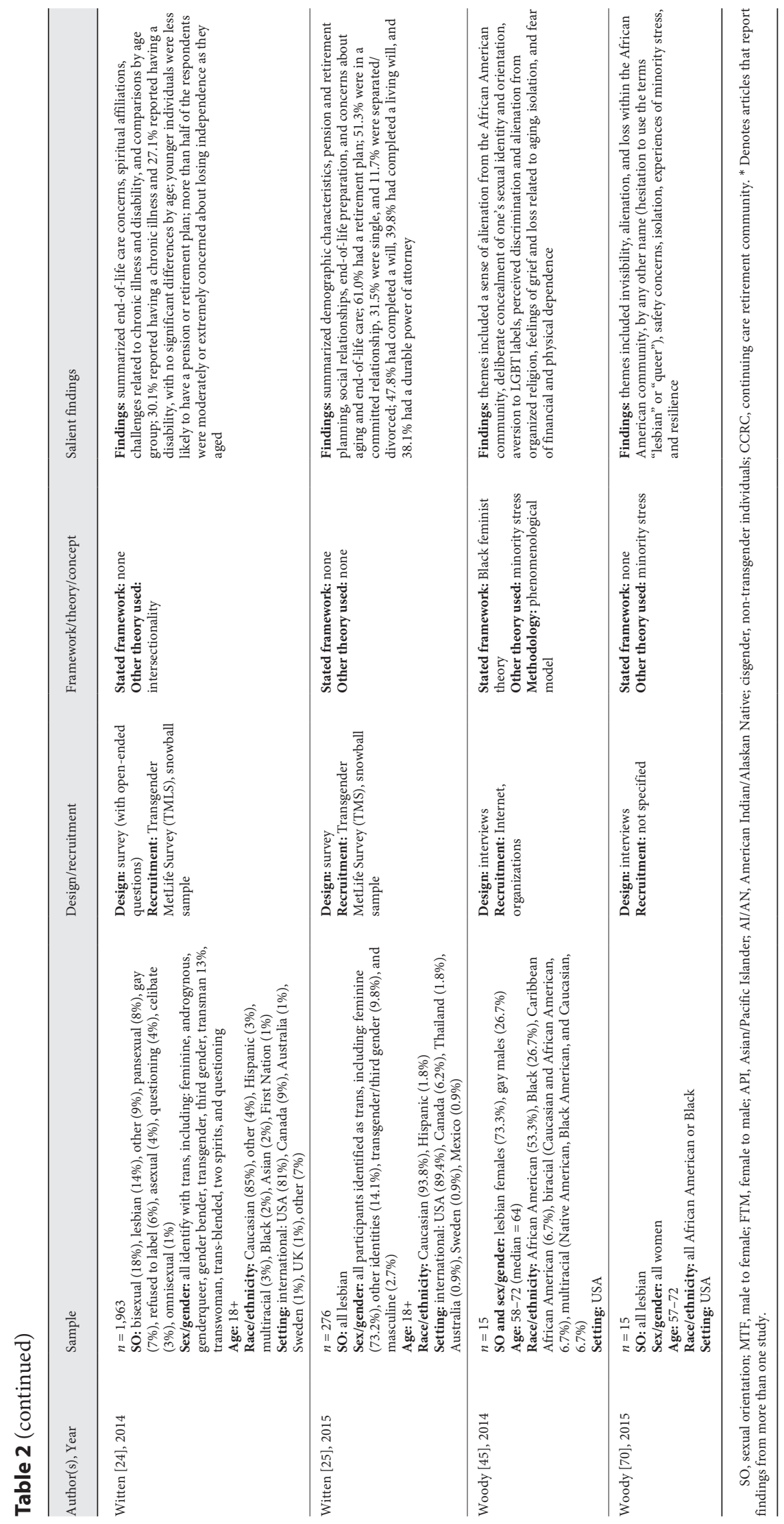


Most samples were made up of a majority of White/ Northern European/Caucasian (hereafter referred to as "White") participants, with 5.6\% of the samples including only White participants $(n=4)$. Among the studies, $34.8 \%$ included African American/Black participants, 31.8\% Hispanic/Latino/a, 21.2\% Asian/Pacific Islanders, 19.7\% Native Americans/Indigenous, and $16.7 \%$ others. About one-quarter (25.8\%) had multiracial participants. Nearly $12 \%(11.3 \%)$ of the samples were $90 \%$ or more White, and another $28.1 \%$ were $80 \%$ or more White. Two studies reported findings from African American or Black participants only, and 1 sample included only Chinese participants. The race/ethnicity of participants was not reported in $19.2 \%$ of the studies, more than half of which were conducted outside of the USA.

\section{Theories Applied}

A conceptual framework was identified in $43.9 \%$ of the articles. Six key theoretical frameworks were used: critical $(12.1 \%, n=8)$, ecological/sociocultural $(7.5 \%, n=5)$, resilience $(7.5 \%, n=5)$, stress $(6.0 \%, n=4)$, positive aging $(4.5 \%, n=3)$, and life course $(3.0 \%, n=2)$ theories. Methodological theories were utilized in $10.0 \%(n=7)$ of the studies. An additional $16.4 \%$ of the articles provided conceptual framing of key concepts, but they were not identified as a theoretical framework for the study.

Critical theories $(10.6 \%, n=8)$ were applied to analyze the ways in which aging is socially constructed through relations of power [44]. As applied, these theories provided a critique of dominant or traditional ways of knowing, challenged common assumptions, examined intersectional identities, and centered the experiences of older adults who are marginalized. Six used ecological and sociocultural frameworks, such as Hierarchical Compensatory Theory [50] and the Anderson Model of service use [51], which were applied to studies on formal and informal service needs and use. A resilience framework was used in 5 studies $[43,59,62-64]$ to investigate social determinants and risk and protective factors, as well as their relationship to aging, health, and well-being. As articulated within the tradition of positive psychology, successful aging was utilized in 3 articles to analyze positive aging-related outcomes among LGBTQ older adults $[17,23,65]$. Stress-related theories, most often the minority stress model $[52,53]$, were used to assess experiences such as loneliness, poor mental health, and service needs [33, 54-56]. A life course perspective was explicitly applied in 2 articles examining life span and life course development [40,57], with several others referencing the "life course" as a key concept, but not as an overarching framework $[16,20,24,36$, 58-61].

Two specific methodological theories were used. Grounded theory was used in $10.6 \%(n=7)$ of the articles to assess the meaning and generation of theory through the analysis of qualitative data [36, 38, 50, 61, 65-67]. Narrative gerontology was used to explore the experiences of older lesbians in attaining sobriety [60]. See Table 3 for the types of theory utilized in the studies.

\section{Key Themes}

In the next section, the systematic review of findings is organized according to the four key domains of the life course (including the interplay of lives with historical times, social relationships, timing of lives, and agency) and an additional domain that included research that extended beyond these life course tenets.

\section{Interplay of Lives and Historical Times}

Consistent with a life course perspective, the interplay of lives and historical times account for the contexts within which LGBTQ older adults have lived, and the most frequent way the literature addressed the impact of this context was through examining traumatic and adverse experiences that LGBTQ older adults encountered because of being perceived as LGBTQ. Existing research focused primarily on discrimination (15\% of the studies) and victimization (12\%) and reported on the frequency $[41,54,59]$ and consequences $[59,63,64]$ of such adverse experiences.

While none of the population-based research studies assessed the prevalence of such traumatic and adverse experiences, a large community-based study reported an average of 6.5 incidents of victimization and/or discrimination over the life course [59]. Rates of lifetime discrimination and victimization were associated with poorer physical health $[59,63]$, disability $[59,63]$, chronic illness [62], depression $[59,63]$, and lower mental health-related quality of life [43]. Such adverse experiences and lack of access to resources over one's lifetime can exacerbate inequalities and result in cumulative disadvantage [75], with multiple negative consequences in later life.

Rates of victimization and discrimination of LGBTQ older adults differed by demographic characteristics; higher rates were associated with being transgender [64], being male [54], and lower socioeconomic status [68]. Other adverse experiences included ageism and alienation within gay communities $[18,69]$, as well as heterosexism in faith-based communities [45, 70]. Qualitative studies documented LGBTQ older adults' experiences 
Table 3. Theoretical perspectives by theory type and authors

\begin{tabular}{|c|c|c|}
\hline Theory type (total $n$ ) & Conceptual framework & Studies [Ref.] \\
\hline \multicolumn{3}{|l|}{ Substantive theories (29) } \\
\hline \multirow[t]{7}{*}{ Critical (8) } & Queer theory and existential time & Fabbre [16] \\
\hline & Queer theory & Fabbre [17], Pilkey [39] \\
\hline & Feminist political economy & Grigorovich [28] \\
\hline & Feminist ethics of care & Grigorovich [29] \\
\hline & Black feminist theory & Woody [45] \\
\hline & Critical gerontology & Kushner et al. [34] \\
\hline & $\begin{array}{l}\text { Post-structuralist conception of } \\
\text { power/resistance }\end{array}$ & Kong [30] \\
\hline \multirow[t]{5}{*}{ Ecological and sociocultural (5) } & Social capital & Erosheva et al. [46] \\
\hline & Social integration & Williams and Fredriksen-Goldsen [47] \\
\hline & $\begin{array}{l}\text { Exchange theory and theory of com- } \\
\text { munal relationships }\end{array}$ & Muraco and Fredriksen-Goldsen [48] \\
\hline & Loneliness model & Kim and Fredriksen-Goldsen [49] \\
\hline & Hierarchical Compensatory Theory & Brennan-Ing et al. [50] \\
\hline Resilience (5) & Resilience framework & Emlet et al. [43], Fredriksen-Goldsen et al. [59, 62-64] \\
\hline \multirow[t]{2}{*}{ Stress-related (4) } & Minority stress model & $\begin{array}{l}\text { Jenkins Morales et al. [54], Kuyper and Fokkema [33], } \\
\text { Stanley and Duong [55] }\end{array}$ \\
\hline & Social stress process & Wight et al. [56] \\
\hline Positive aging (3) & Successful aging & Fabbre [17], Porter et al. [23], Van Wagenen et al. [65] \\
\hline \multirow[t]{3}{*}{ Other (4) } & Life course perspective & Fabbre [16], Orel [57] \\
\hline & Meaning making & Gabrielson [71] \\
\hline & Perceived control & Hostetler $[40]$ \\
\hline \multirow[t]{2}{*}{ Methodological theories (8) } & Grounded theory & $\begin{array}{l}\text { Brennan-Ing et al. [50], Parslow and Hegarty [38], } \\
\text { Putney [66], Rosenfeld [67], Siverskog [36], Sullivan } \\
\text { [61], Van Wagenen et al. [65] }\end{array}$ \\
\hline & Narrative gerontology & Rowan and Butler $[60]$ \\
\hline
\end{tabular}

and concerns of discrimination, mistreatment, and neglect in service settings such as in-home care, workplaces, and health care settings $[29,34,61,71,72]$.

Internalized stigma, i.e., having negative views of one's own sexual or gender identities, was also often conceptualized as resulting from the historical and cultural context of LGBTQ older adults' lives. For example, 4 studies reported findings related to internalized stigma, which was associated with higher rates of depression and disability [64], loneliness [49], poor physical health [63], and poor quality of life [43]. Internalized gay ageism among older gay men was associated with higher rates of depression [56].

Linked and Interdependent Lives

Embedded within social networks of families of choice, kin, friends, and legally defined family members, the most common social relationships studied were with spouses and partners $[47,49,59,63,80,81]$, friends and peer relationships [37, 41, 50, 71, 82], followed by children [46], informal caregivers $[50,80]$, other household members [20], and pets [66]. Broader social networks and supports were also investigated $[32,33,46]$. Social relationships and social networks were assessed for their presence, size, and impact. One study found that same-sex relationships may be uniquely protective, as same-sex couples reported fewer chronic conditions and were less likely to report poor health than heterosexual couples [21]. Being partnered, having greater social support, and having larger social networks were associated with positive quality of life $[59,81]$, lower rates of disability, and fewer symptoms of depression [63].

Greater levels of social support were observed among women [63] and younger participants [59]. Social networks were also larger among women $[46,63]$, younger individuals $[46,59]$, trans individuals, and those living 
with children [46]. Having a partner and co-residing with that partner were associated with being White [49], younger $[47,59]$, and female [80]. Loneliness and social isolation, on the other hand, were associated with being male, being single, being less socially embedded, and having a smaller social network $[32,33]$.

A few studies investigated the importance of informal supports $[28,60,62]$ and the likelihood of having an informal caregiver $[50,73,80]$. Among LGBTQ older adults, $20 \%$ indicated that they were currently providing informal care [80]; caregivers reported a strong sense of duty [38], but also love and commitment, particularly among caring spouses, partners, and close friends [48]. Relationship quality was protective against depression for both informal caregivers and those receiving care [62].

\section{Timing of Lives}

The life events explored in the literature were related primarily to identity development, coming out and disclosure experiences $[16,17,41]$, and the formation and dissolution of important social relationships [32, 41, 77]. Coming out experiences were measured in a variety of ways, including sequencing and timing. In terms of identity development trajectories, older lesbians, for example, reported recognizing attractions to women at an average age of 18 years and beginning their first serious relationship with a woman 6.5 years later [41]. In a qualitative study, older gay men reported a sequencing of sexual experiences and identity development. For example, many reported experiencing same-sex sexual contact, followed by a period of non-acceptance of self, which was most often followed by self-acceptance [35].

Overall rates of disclosure were assessed: $73 \%$ of lesbian, gay, and bisexual adults in a large sample reported being out and comfortable with their sexual orientation [57]. Showing variation by context, $91.5 \%$ of older lesbians reported being out to their family, but only $48.5 \%$ were out to their health care providers [41]. Of trans older adults, $93.7 \%$ were mostly or completely out in terms of their gender identity, but only $22.8 \%$ openly identified in religious organizations [23]. Differences in disclosure rates were associated with multiple factors. Lower rates of disclosure were reported by older adults [59], those with smaller social networks [46], and those living in rural areas [83]. Lower disclosure rates were also associated with higher levels of depression and anxiety [64]. A few qualitative studies described the potential risks of identity disclosure $[57,67]$ and potential protective responses such as withholding biographical information (e.g., gender of one's partner); policing body, dress, or mannerisms; and avoiding or even ridiculing other LGBTQ individuals to blend in [67].

Life events related to the dissolution and ending of social relationships were investigated. For example, LGBTQ older adults were more likely than heterosexuals to have been divorced [32]. Gay men were more likely to have experienced the death of a partner than lesbians, bisexuals, and heterosexuals [32], and often at younger ages, with an especially high rate of death-related experiences as a result of HIV/AIDS [77]. Thirteen percent of lesbians also reported the death of a partner [41]. Experiencing the death of a partner was linked to experiences of disenfranchised grief and legal and financial concerns [37, 84].

\section{Human Agency}

Human agency, accounting for how individuals take action to influence their own life possibilities, was most often explored relative to resilience, as individuals responded proactively to various adverse life situations [59, 60] and hostile environments [70], such as choosing to ignore or confront oppressive behaviors or using one's "ageing capital to challenge gay ageism" [18]. A few studies highlighted the important role of resistance to marginalization and heteronormativity $[30,39,59]$ in the lives of LGBTQ older adults.

Protective factors as indicators of agency and resilience were investigated [59], including self-esteem, selfefficacy, mastery, hope, and a positive sense of sexual identity. Higher levels of self-esteem and self-efficacy were associated with being older [25] and having a better quality of life [43, 59]. Mastery [77] and hope [31] were associated with positive mental health outcomes. Three qualitative studies identified resilience as a theme, illustrating the ability to bounce back from adverse situations [60], respond to hostile environments [70], and decrease vulnerability in later life [18]. Specific examples included gay men's development of an underground or counterculture $[30,35]$, and reinterpreting one's failure to comply with heteronormative life sequences and expectations as a way to redefine success in the narratives of older trans adults [17].

Extending beyond Elders' Life Course Perspective

Several areas of existing LGBTQ aging research did not fit neatly into the life course tenets, such as elder abuse, spirituality, service use and needs, and positive and negative health behaviors and outcomes. For example, other types of adverse experiences were reported that were not directly linked in the literature to historical times, such as elder abuse and neglect. Among lesbian, gay, and bisexu- 
al adults aged 60 years and older who attended community-based social and recreational programs, $22.1 \%$ reported having experienced at least one type of abuse from their caregiver, with $11.5 \%$ reporting more than one type [73]. The most common types of abuse were emotional, verbal, physical, and neglect. In a study of transgender older adults, two-thirds reported having received unwanted sexual touch, with 55\% reporting such abuse was related to their perceived gender expression or presentation [74].

The study of religiosity and spirituality in the lives of LGBTQ older adults was often presented in the literature as a personal resource and assessed using a variety of indicators, including religious or spiritual affiliation, the frequency of religious activity, and personal experiences in religious and spiritual institutions. Although lesbian, gay, and bisexual older adults were found to be less frequent churchgoers than their heterosexual counterparts [32], nearly $40 \%$ attended religious or spiritual services on an ongoing basis [59]. Religious and spiritual activity, such as engagement, was not significantly associated with health or quality of life for LGBTQ older adults in general [59] or with successful aging among trans older adults [23].

A new theme that emerged in the LGBTQ aging-related literature was health, including physical health, mental health, health behaviors, and health-related quality of life and well-being. Much of this research addressed poor health, although some studies found that LGBTQ older adults reported good mental health [41,73], physical health $[59,63,64]$, and quality of life [59]. Yet there was mounting evidence that LGBTQ older adults experienced health disparities, with higher rates of poor general health, disability, functional impairment, and psychological distress than among heterosexuals of similar age [20,64]. While health disparities were evident across the LGBTQ groups, those identified at elevated risk included transgender [64], bisexual [63, 76], lesbian [63], and unemployed [77] older adults, as well as those needing caregiving assistance [62]. One study on a large sample of LGBTQ older adults found that 9\% reported an HIV diagnosis [43], while up to one-third of gay men in another study had a diagnosis of HIV [77]. The progression of HIV to AIDS and comorbidities were negatively associated with quality of life [43].

Findings related to LGBTQ older adults' health and age were mixed. In one large community-based sample, quality of life was highest among the middle-aged group (65-79 years) and similar among the younger (50-64 years) and oldest (80+ years) groups [59], but another study found that the youngest participants (55-64 years) reported the highest rates of anxiety and posttraumatic stress disorder [76]. The oldest LGBTQ adults reported the most chronic conditions and lowest physical healthrelated quality of life $[59,49]$.

Behavioral health, including the use of tobacco, alcohol, and illicit substances $[42,55,63,76]$ and sexual behavior [42], was another common focus identified in the literature that did not align directly with the life course tenets. In terms of demographic differences, lesbian, gay, and bisexual older men and women, compared to heterosexuals, were at an elevated risk of excessive drinking [20]. Among older men, bisexuals were less likely to have engaged in unprotected sexual activity but more likely to be smokers than gay men [40]. For trans older adults, physical activity was negatively associated with rates of poor physical health, disability, and depression and anxiety; trans older adults reported less engagement in physical activity than did cisgender sexual minorities [64]. There was also evidence that substance use was related to sexual risk behavior; for example, among gay and bisexual older men living with HIV, unprotected sex was not predicted by past or current alcohol use but was associated with current and lifetime use of crystal meth, cocaine, and club drugs (e.g., GHB, ketamine, and Ecstasy) [42]. Fewer studies considered positive health behaviors, although a few assessed physical and leisure activities [59, $63,64]$, which were associated with better quality of life and lower rates of depression $[59,63]$.

Some studies indicated barriers to care. In a population-based study, sexual-minority older women were more likely than heterosexual women to experience financial barriers to health care [20]. Additional barriers included difficulty locating needed services [78], past negative experiences in care settings $[57,78]$, and fears of discrimination $[24,36,63,79]$. Despite barriers to care, compared to heterosexuals, sexual minorities reported higher service use in some areas. For example, lesbian, gay, and bisexual older adults were more likely to have received a flu shot, HIV screening [20], and counseling services [55].

Commonly reported aging-related concerns of LGBTQ older adults included loss of decision-making ability, loss of independence, lack of availability of assistance from others, economic concerns [24-26, 77], and needs regarding legal planning, including durable powers of attorney, end-of-life decision-making, and retirement plans $[23,25,68,84,85]$. Studies also identified the need for nonjudgmental and proactive welcoming, affirming, and sensitive services $[28,29]$ and a critical need for train- 
ing of health and human service providers and organizations to promote cultural capacity in the delivery of services [28].

\section{Discussion}

This review provides a much-needed updated evidence base for LGBTQ aging research. Since our prior review [7], the research on the topic has grown rapidly, as illustrated by the sheer increase in frequency of articles; this review included 66 articles published over 8 years in comparison to 58 articles during the prior 25 -year review period. In the previous review, we noted the surprising absence of health research in the field, given its central role in the gerontological literature in general. However, in this review health-related research emerged as a new 5 th wave of work in the field, as several studies addressed health disparities and inequities, as well as social determinants associated with the health and well-being of LGBTQ older adults. Below, we discuss the key advancements and limitations of the existing literature, as well as outline a blueprint for future LGBTQ aging research across theoretical, substantive, and methodological domains.

\section{Theory: Where from Here?}

The use of theory in this literature has increased significantly since the last review, with $43.9 \%$ of the articles stating a conceptual framework, up from $25.0 \%$ in the prior review. Interestingly, critical theories were the most commonly used perspectives in the LGBTQ aging literature along with methodological theories, followed by ecological/sociocultural, resilience, stress, positive aging, and life course. Critical theories were presented as challenging common assumptions and traditional ways of knowing by centering the experiences of those who are marginalized or excluded from dominant society [44]. Fabbre's [17] use of queer theory, for example, was used to assess successful aging and critiqued the notion of "success" in the broader field of gerontology and offered a reimagined understanding of failure in the lives of transgender older adults. While the use of theory has grown, more depth, integration, and review of the field continue to be needed for framing research questions as well as analysis and interpretation.

While historical forces and linked lives from the life course perspective [8] were evident in the previous review, both the timing of lives and human agency had rarely been assessed earlier. We now see small and growing literature bases in both these areas. However, we also found that key areas of LGBTQ aging research did not fit neatly into Elder's [8] four tenets of the life course, including spirituality, elder abuse, positive and negative health outcomes, health behaviors, and service use and needs.

To more fully capture the possibilities of the growing field of aging in historically disadvantaged and marginalized populations, we propose the Iridescent Life Course, much like iridescent properties [86] encompassing the interplay of light and environment creating dynamic and fluid colors as perceived from different angles and perspectives over time. The Iridescent Life Course extends existing work in the following ways as it:

- incorporates the intersectionality of sexuality and gender as well as other social positions and considers how these positions interact to shape opportunities and constraints;

- addresses the fluidity inherent across identities as well as how they interact with each other to reflect aging lives as they shift over time;

- highlights the consequences of divergent representations and viewpoints of and about disadvantaged older adults and their interaction with individual, interpersonal, social, and structural opportunities and barriers;

- illuminates the social construction and power dynamics inherent in the lived lives of marginalized older adults, such as through queering and trans-forming of the life course, which sheds light on the heterosexual and gender-normative nature of most existing gerontological research; and

- elucidates psychological, behavioral, and biological factors that influence the lives of older adults, along with critical social factors.

The Iridescent Life Course raises questions regarding the utility and potential overuse of "LGBTQ" as an umbrella term, given the intersectional nature of aging across communities, as well as the critical role of culture, time, and space [17]. An important new direction for this research is intersectionality, i.e., to assess the complex nature of intersecting demographic, social, cultural, and societal positions including diverse ages and sexual and gender identities and their multiple junctures over the life course. Within a life course perspective, this highlights the rapidly changing social context and raises important generational issues for future study. Yet, to date, most research has ignored heterogeneity within older adult communities. Exploring such variations and similarities over the life course within intersecting multiple 
social and structural positions that can be simultaneously occupied will foster a much deeper understanding of life course trajectories. However, the demographic characteristics of samples continue to be underreported in the literature, constricting the generalization of the findings. Nearly one-quarter of the studies, for example, did not report the race or ethnicity of the research participants.

Additional investigation of the consequences of divergent representations and viewpoints in society and the interaction with individual, interpersonal, social, and structural opportunities and barriers is needed. For example, the lack of attention to poverty and economic inequities, socioeconomic status, class, ethnicity, race, nationality, immigration, and ability status in this field is alarming, especially since we know that stratification and inequities have such far-reaching effects across the life course. While research on those who identify as trans or queer was represented in the existing literature, it comprised a small portion of the studies; thus, more work is needed in these areas. In addition, other subpopulations also require additional study, including the oldest, bisexual (especially women), asexual, intersex, and sexual and gender non-binary and diverse older adults; they continue to remain largely invisible in research, despite evidence of distinct experiences.

\section{Substantive Areas of Study: Depth rather than \\ Breadth}

Differing Configurations of Risks and Resources

As we move forward, it is critical that the field reach for more depth in research rather than continuing to increase breadth. Several existing studies have illustrated differing configurations of risks and resources in the lives of LGBTQ older adults [20,64] both by subgroups as well as by differing outcomes. Future research is needed to further investigate LGBTQ older adults within the larger social context as well as embedded within kin relations and communities, and to assess how these structures and relationships may play a significant role in aging. While more research investigating health disparities is needed, we run the risk of overproblematizing and overmedicalizing LGBTQ older adults unless we also invest in complementary areas such as resistance, resilience, and community engagement, as well as positive health behaviors and outcomes in the lives of LGBTQ older adults (e.g., well-being, life satisfaction, and quality of life).
Trauma and Inequities in Visibility, Representation, and Capital

Future research needs to further investigate how trauma, discrimination, and bias has resulted in differing consequences for LGBTQ older adults over time, depending in part on their age, generation, and vulnerability. Also needed are studies that address access to aging and health systems and LGBTQ older adults' use of services. The next wave of research needs to address both individual and community agency that capitalizes on the strengths and benefits of LGBTQ people, and their communities and social movements. Research is also needed to inform policymakers on how legislative processes and policies shape the larger social context as they provide access to social representation and resources since they influence health and well-being over time.

\section{Multilevel Analysis of LGBTQ Aging over Time}

To more fully understand the complex interaction of such factors will require multiple levels of analysis - including individual and intrapersonal (e.g., comfort with one's identity), interpersonal and social (e.g., disclosure to others), and structural levels (e.g., geographical, existence or absence of legal protection, and the larger sociopolitical context). Studies are needed that address the multiple levels and intersecting influences on the full continuum of LGBTQ aging, well-being, and quality of life, including positive and adverse pathways (behavioral, social, psychological, and biological processes) to influence the continuum of aging outcomes in LGBTQ communities [87]. And while most research relies on self-report measures, the use of more objective data is needed, including functional and cognitive assessments and biomarker and physiological data, to better understand environmental and biological influences of aging and health over time.

All studies reviewed to date were cross-sectional, with no longitudinal findings reported, which limits our ability to assess trajectories and causal relationships as well as to identify those at the greatest risk and most vulnerable in these communities. Understanding individual as well as cohort trajectories in LGBTQ aging will be aided by the development of longitudinal studies that can attend to the shifting individual, structural, and environmental contexts over time. Such longitudinal approaches have the capacity to be responsive to tensions that result from heterogeneous needs given the diverse nature of these communities and the call for system-level changes, which in the past have often been built upon the premise of homogeneous experiences. Such studies can also create oppor- 
tunities to develop, design, and evaluate evidence-based interventions in order to address the needs of LGBTQ older adults and of their families and communities.

\section{Methodological Advances}

The findings from this review reveal a greater differentiation and complexity in methods since the prior review. Overall, the research designs were more varied, primarily relying on quantitative or qualitative data, with a few mixed-method studies. There was more diversity within samples, and for the first time some studies incorporated population-based data. While most were largely descriptive, there was an increase in correlational and comparative studies. The state of the knowledge in the field provides greater opportunity for mixed-method studies as well as for meta-analyses of specific substantive topics. However, the field continues to grapple with several measurement issues. For example, there remains a tendency to conflate concepts, such as sex, sexual orientation, gender, and gender identity and expression. For instance, some studies measured sex as "male" or "female," but referred to the participants as "men" or "women," or reported findings for lesbian, gay, bisexual, and transgender individuals, with "transgender" being analyzed as a sexual identity. The field needs to better distinguish and differentiate research on sexual orientation and gender, which will require deeper analyses of the various aspects of sexual orientation (e.g., sexual identity, sexual behavior, attraction and romantic relationships, and other types of diversity in sexuality) and gender (e.g., gender identity, gender expression, and gender diversity and non-binarity), as well as assessing how these dimensions change or remain static over the life span. The development of best practices and standardization of measures of such constructs is needed. Next steps will also require developing representative sampling methods while continuing to attend to the need for innovative methods to reach hidden-within-hidden populations.

\section{Global Initiatives}

The interplay of culture and the importance of understanding LGBTQ lives on a global scale are essential to understanding differences and similarities across local as well as national contexts. Advancing global LGBTQ aging research initiatives has the potential to create important opportunities for the field. As we move forward, it will be critical to assess human rights such as participation, representation, transparency, and accountability within differing and shifting cultural contexts. Evaluating changes in policy will also be facilitated by global research partner- ships that allow for cross-national comparisons. Such information would be useful in the development and evaluation of evidence-based prevention efforts, interventions, practices, training, and policy.

\section{Conclusions}

This review of the literature was designed to provide an evidence-based platform for future research. Since the prior review, several promising trends have become evident, including the increased application of theory, the use of more varied research designs and methods, and the emergence of a new wave of research on the health and well-being of LGBTQ older adults. While the topics have grown in breadth, future research must strive for greater depth. The Iridescent Life Course underscores the need for more fully encompassing the intersectionality and fluidity inherent in aging. Several understudied areas ripe for further study include the complex nature of intersecting demographic, cultural, and sociopolitical positions; differing configurations in risks and resources; legacies of trauma and inequities in representation and capital; multilevel analyses; the use of longitudinal studies to assess trajectories over time; and growing opportunities for collaborations through global initiatives.

\section{Acknowledgements}

Research reported in this publication was supported by the $\mathrm{Na}$ tional Institute on Aging of the National Institutes of Health under Award No. R01AG026526 (K.I.F.G., principal investigator). The content is solely the responsibility of the authors and does not necessarily represent the official views of the National Institutes of Health.

\section{Statement of Ethics}

The authors have no ethical conflicts to disclose.

\section{Disclosure Statement}

The authors have no conflicts of interest to disclose. 


\section{References}

1 Schist K, Westbrook L. Doing gender, doing heteronormativity: "gender normals," transgender people, and the social maintenance of heterosexuality. Gend Soc. 2009 Aug;23(4): 440-64.

2 Pew Research Center. Changing attitudes on gay marriage. 2016. Available from: http:// www.pewforum.org/2016/05/12/changingattitudes-on-gay-marriage/.

3 Institute of Medicine (IOM). The health of lesbian, gay, bisexual, and transgender people: building a foundation for better understanding. Washington (DC): The National Academic Press; 2011. Available from: https:// www.nap.edu/catalog/13128/the-healthof-lesbian-gay-bisexual-and-transgenderpeople-building.

4 Vincent GK, Velkoff VA. The next four decades: the older population in the United States: 2010 to 2050. U.S. Census Bureau and U.S. Department of Commerce; 2010. Available from: http://www.aarp.org/content/ dam/aarp/livable-communities/old-learn/ demographics/the-next-four-decades-theolder-population-in-the-united-states2010-2050-aarp.pdf.

5 World Health Organization (WHO). Facts about ageing. 2014. Available from: http:// www.who.int/ageing/about/facts/en/.

6 Fredriksen-Goldsen KI, Kim HJ. The science of conducting research with LGBT older adults - an introduction to Aging with Pride: National Health, Aging, and Sexuality/Gender Study (NHAS). Gerontologist. 2017 Feb; 57 suppl 1:S1-14.

7 Fredriksen-Goldsen KI, Muraco A. Aging and sexual orientation: a 25 -year review of the literature. Res Aging. 2010 May;32(3):372413.

8 Elder GH Jr. Time, human agency, and social change: perspectives on the life course. Soc Psychol Q. 1994;57(1):4-15.

9 Dilworth-Anderson P, Williams IC, Gibson $B E$. Issues of race, ethnicity, and culture in caregiving research: a 20 -year review (19802000). Gerontologist. 2002 Apr;42(2):237-72.

10 Inelman EM, Gasparini G, Enzi G. HIV/AIDS in older adults: a case report and literature review. Geriatrics. 2005 Sep;60(9):26-30.

11 Roelfs DJ, Shor E, Falzon L, Davidson KW, Schwartz JE. Meta-analysis for sociology: a measure-driven approach. Bull Methodol Sociol. 2013 Jan;117(1):75-92.

12 Sankar A, Nevedal A, Neufeld S, Berry R, Luborsky M. What do we know about older adults and HIV? A review of social and behavioral literature. AIDS Care. 2011 Oct;23(10): 1187-207.

13 Bennett DS, Traub K, Mace L, Juarascio A, O'Hayer CV. Shame among people living with HIV: a literature review. AIDS Care. 2016;28(1):87-91.
14 Mukolo A, Villegas R, Aliyu M, Wallston KA. Predictors of late presentation for HIV diagnosis: a literature review and suggested way forward. AIDS Behav. 2013 Jan;17(1):5-30.

15 Smit PJ, Brady M, Carter M, Fernandes R, Lamore L, Meulbroek M, et al. HIV-related stigma within communities of gay men: a literature review. AIDS Care. 2012;24(4):40512.

16 Fabbre VD. Gender transitions in later life: the significance of time in queer aging. Gerontol Soc Work. 2014;57(2-4):161-75.

17 Fabbre VD. Gender transitions in later life: a queer perspective on successful aging. Gerontologist. $2015 \mathrm{Feb} ; 55(1): 144-53$.

18 Simpson P. Alienation, ambivalence, agency: middle-aged gay men and ageism in Manchester's gay village. Sexualities. 2013;16(3-4): 283-99.

19 Fredriksen-Goldsen KI, Kim HJ. Count me in: response to sexual orientation measures among older adults. Res Aging. 2015 Jul; 37(5):464-80.

20 Fredriksen-Goldsen KI, Kim HJ, Barkan SE, Muraco A, Hoy-Ellis CP. Health disparities among lesbian, gay, and bisexual older adults: results from a population-based study. Am J Public Health. 2013 Oct;103(10):1802-9.

21 Gonzales G, Henning-Smith C. Disparities in health and disability among older adults in same-sex cohabiting relationships. J Aging Health. 2015 Apr;27(3):432-53.

22 Che A, Siemens I, Fejtek M, Wassersug RJ. The influence of political jurisdiction, age, and sex on handholding in public by same-sex couples. J Homosex. 2013;60(11):1635-46.

23 Porter KE, Ronneberg CR, Witten TM. Religious affiliation and successful aging among transgender older adults: findings from the Trans MetLife Survey. J Relig Spirit Aging. 2013;25(2):112-38

24 Witten TM. End of life, chronic illness, and trans-identities. J Soc Work End Life Palliat Care. 2014;10(1):34-58.

25 Witten TM. Elder transgender lesbians: exploring the intersection of age, lesbian sexual identity, and transgender identity. J Lesbian Stud. 2015;19(1):73-89.

26 Hughes M. Lesbian and gay people's concerns about ageing and accessing services. Aust Soc Work. 2009;62(2):186-201.

27 Lyons A, Pitts M, Grierson J. Growing old as a gay man: psychosocial well-being of a sexual minority. Res Aging. 2013;35(3):275-95.

28 Grigorovich A. Restricted access: older lesbian and bisexual women's experiences with home care services. Res Aging. 2015 Oct; 37(7):763-83

29 Grigorovich A. The meaning of quality of care in home care settings: older lesbian and bisexual women's perspectives. Scand J Caring Sci. 2016 Mar;30(1):108-16.

30 Kong TS. A fading Tongzhi heterotopia: Hong Kong older gay men's use of spaces. Sexualities. 2012;15(8):896-916.
31 Sagie O. Predictors of well-being among older gays and lesbians. Soc Indic Res. 2015;120(3): 859-70.

32 Fokkema T, Kuyper L. The relation between social embeddedness and loneliness among older lesbian, gay, and bisexual adults in the Netherlands. Arch Sex Behav. 2009 Apr; 38(2):264-75.

33 Kuyper L, Fokkema T. Loneliness among older lesbian, gay, and bisexual adults: the role of minority stress. Arch Sex Behav. 2010 Oct; 39(5):1171-80.

34 Kushner B, Neville S, Adams J. Perceptions of ageing as an older gay man: a qualitative study. J Clin Nurs. 2013 Dec;22(23-24):338895.

35 Neville S, Kushner B, Adams J. Coming out narratives of older gay men living in New Zealand. Australas J Ageing. 2015 Oct;34(2 Suppl 2):29-33.

36 Siverskog A. "They just don't have a clue": transgender aging and implications for social work. J Gerontol Soc Work. 2014;57(2-4): 386-406.

37 Almack K, Seymour J, Bellamy G. Exploring the impact of sexual orientation on experiences and concerns about end of life care and on bereavement for lesbian, gay, and bisexual older people. Sociology. 2010;44(5):908-24.

38 Parslow O, Hegarty P. Who cares? UK lesbian caregivers in a heterosexual world. Womens Stud Int Forum. 2013;40:78-86.

39 Pilkey B. Queering heteronormativity at home: older gay Londoners and the negotiation of domestic materiality. Gend Place Cult. 2014;21(9):1142-57.

40 Hostetler AJ. Community involvement, perceived control, and attitudes toward aging among lesbians and gay men. Int J Aging Hum Dev. 2012;75(2):141-67.

41 Averett P, Yoon I, Jenkins CL. Older lesbians: experiences of aging, discrimination and resilience. J Women Aging. 2011;23(3):216-32.

42 Brennan-Ing M, Porter KE, Seidel L, Karpiak SE. Substance use and sexual risk differences among older bisexual and gay men with HIV . Behav Med. 2014;40(3):108-15.

43 Emlet CA, Fredriksen-Goldsen KI, Kim HJ. Risk and protective factors associated with health-related quality of life among older gay and bisexual men living with HIV disease. Gerontologist. 2013 Dec;53(6):963-72.

44 Ray RE. Researching to transgress: the need for critical feminism in gerontology. J Women Aging. 1999;11(2-3):171-84.

45 Woody I. Aging out: a qualitative exploration of ageism and heterosexism among aging African American lesbians and gay men. J Homosex. 2014;61(1):145-65.

46 Erosheva EA, Kim HJ, Emlet C, FredriksenGoldsen KI. Social networks of lesbian, gay, bisexual, and transgender older adults. Res Aging. 2016 Jan;38(1):98-123. 
47 Williams ME, Fredriksen-Goldsen KI. Samesex partnerships and the health of older adults. J Community Psychol. 2014 Jul;42(5): 558-70.

48 Muraco A, Fredriksen-Goldsen KI. The highs and lows of caregiving for chronically ill lesbian, gay, and bisexual elders. J Gerontol Soc Work. 2014;57(2-4):251-72.

49 Kim HJ, Fredriksen-Goldsen KI. Living arrangement and loneliness among lesbian, gay, and bisexual older adults. Gerontologist. 2016 Jun;56(3):548-58.

50 Brennan-Ing M, Seidel L, Larson B, Karpiak SE. Social care networks and older LGBT adults: challenges for the future. J Homosex. 2014;61(1):21-52.

51 Brennan-Ing M, Seidel L, London AS, Cahill S, Karpiak SE. Service utilization among older adults with HIV: the joint association of sexual identity and gender. J Homosex. 2014; 61(1):166-96.

52 Meyer IH. Minority stress and mental health in gay men. J Health Soc Behav. 1995 Mar; 36(1):38-56.

53 Meyer IH. Prejudice, social stress, and mental health in lesbian, gay, and bisexual populations: conceptual issues and research evidence. Psychol Bull. 2003 Sep;129(5):674-97.

54 Jenkins Morales M, King MD, Hiler H, Coopwood MS, Wayland S. The Greater St. Louis LGBT Health and Human Services Needs Assessment: an examination of the Silent and Baby Boom generations. J Homosex. 2014; 61(1):103-28.

55 Stanley IH, Duong J. Mental health service use among lesbian, gay, and bisexual older adults. Psychiatr Serv. 2015 Jul;66(7):743-9.

56 Wight RG, LeBlanc AJ, Meyer IH, Harig FA. Internalized gay ageism, mattering, and depressive symptoms among midlife and older gay-identified men. Soc Sci Med. 2015 Dec; 147:200-8.

57 Orel NA. Investigating the needs and concerns of lesbian, gay, bisexual, and transgender older adults: the use of qualitative and quantitative methodology. J Homosex. 2014; 61(1):53-78.

58 Averett P, Yoon I, Jenkins CL. Older lesbian sexuality: identity, sexual behavior, and the impact of aging. J Sex Res. 2012;49(5):495507.

59 Fredriksen-Goldsen KI, Kim HJ, Shiu C, Goldsen J, Emlet CA. Successful aging among LGBT older adults: physical and mental health-related quality of life by age group. Gerontologist. 2015 Feb;55(1):154-68.
60 Rowan NL, Butler SS. Resilience in attaining and sustaining sobriety among older lesbians with alcoholism. J Gerontol Soc Work. 2014; 57(2-4):176-97.

61 Sullivan KM. Acceptance in the domestic environment: the experience of senior housing for lesbian, gay, bisexual, and transgender seniors. J Gerontol Soc Work. 2014;57(2-4): 235-50.

62 Fredriksen-Goldsen KI, Kim HJ, Muraco A, Mincer S. Chronically ill midlife and older lesbians, gay men, and bisexuals and their informal caregivers: the impact of the social context. Sex Res Soc Policy. 2009;6(4):52-64.

63 Fredriksen-Goldsen KI, Emlet CA, Kim HJ, Muraco A, Erosheva EA, Goldsen J, et al. The physical and mental health of lesbian, gay male, and bisexual (LGB) older adults: the role of key health indicators and risk and protective factors. Gerontologist. 2013 Aug; 53(4):664-75.

64 Fredriksen-Goldsen KI, Cook-Daniels L, Kim HJ, Erosheva EA, Emlet CA, Hoy-Ellis CP, et al. Physical and mental health of transgender older adults: an at-risk and underserved population. Gerontologist. 2014 Jun;54(3):488500.

65 Van Wagenen A, Driskell J, Bradford J. "I'm still raring to go": successful aging among lesbian, gay, bisexual, and transgender older adults. J Aging Stud. 2013 Jan;27(1):1-14.

66 Putney JM. Older lesbian adults' psychological well-being: the significance of pets. J Gay Lesbian Soc Serv. 2014;26(1):1-17.

67 Rosenfeld D. Heteronormativity and homonormativity as practical and moral resources: the case of lesbian and gay elders. Gend Soc. 2009;23(5):617-38.

68 Valenti K, Katz A. Needs and perceptions of LGBTQ caregivers: the challenges of services and support. J Gay Lesbian Soc Serv. 2014; 26(1):70-90.

69 Slevin KF, Linneman TJ. Old gay men's bodies and masculinities. Men Masculinities. 2010;12(4):483-507.

70 Woody I. Lift every voice: voices of AfricanAmerican lesbian elders. J Lesbian Stud. 2015; 19(1):50-8.

71 Gabrielson ML. "I will not be discriminated against": older lesbians creating new communities. ANS Adv Nurs Sci. 2011 Oct-Dec; 34(4):357-73.

72 Stein GL, Beckerman NL, Sherman PA. Lesbian and gay elders and long-term care: identifying the unique psychosocial perspectives and challenges. J Gerontol Soc Work. 2010; 53(5):421-35.

73 Grossman AH, Frank JA, Graziano MJ, Narozniak DR, Mendelson G, El Hassan D, et al. Domestic harm and neglect among lesbian, gay, and bisexual older adults. J Homosex. 2014;61(12):1649-66.
74 Cook-Daniels L, Munson M. Sexual violence, elder abuse, and sexuality of transgender adults, age 50+: results of three surveys. J GLBT Fam Stud. 2010;6(2):142-77.

75 O'Rand AM. The precious and the precocious: understanding cumulative disadvantage and cumulative advantage over the life course. Gerontologist. 1996 Apr;36(2):230-8.

76 Jessup MA, Dibble SL. Unmet mental health and substance abuse treatment needs of sexual minority elders. J Homosex. 2012;59(5): 656-74.

77 Wight RG, LeBlanc AJ, de Vries B, Detels R. Stress and mental health among midlife and older gay-identified men. Am J Public Health. 2012 Mar; 102(3):503-10.

78 Czaja SJ, Sabbag S, Lee CC, Schulz R, Lang S, Vlahovic $\mathrm{T}$, et al. Concerns about aging and caregiving among middle-aged and older lesbian and gay adults. Aging Ment Health. 2016 Nov;20(11):1107-18.

79 Gardner AT, de Vries B, Mockus DS. Aging out in the desert: disclosure, acceptance, and service use among midlife and older lesbians and gay men. J Homosex. 2014;61(1):129-44.

80 Croghan CF, Moone RP, Olson AM. Friends, family, and caregiving among midlife and older lesbian, gay, bisexual, and transgender adults. J Homosex. 2014;61(1):79-102.

81 Kelly-Campbell RJ, Atcherson SR. Perception of quality of life for adults with hearing impairment in the LGBT community. J Commun Disord. 2012 Sep-Oct;45(5):367-77.

82 Gabrielson ML, Holston EC, Dyck MJ. Are they family or friends? Social support instrument reliability in studying older lesbians. J Homosex. 2014;61(11):1589-604.

83 Lee MG, Quam JK. Comparing supports for LGBT aging in rural versus urban areas. J Gerontol Soc Work. 2013;56(2):112-26.

84 Jenkins CL, Edmundson A, Averett P, Yoon I. Older lesbians and bereavement: experiencing the loss of a partner. J Gerontol Soc Work. 2014;57(2-4):273-87.

85 MetLife Mature Market Institute. Out and aging: the MetLife Study of Lesbian and Gay Baby Boomers. J GLBT Fam Stud. 2010;6(1): 40-57.

86 Martin G. Collins English Dictionary (Reference edition). NYC: McGraw Hill; 2016.

87 Fredriksen-Goldsen KI, Simoni JM, Kim HJ, Lehavot K, Walters KL, Yang J, et al. The health equity promotion model: reconceptualization of lesbian, gay, bisexual, and transgender (LGBT) health disparities. Am J Orthopsychiatry. 2014 Nov;84(6):653-63. 